\title{
Term-limit evasions and the non-compliance cycle
}

\author{
Zachary Elkins ${ }^{1}$
}

Accepted: 20 April 2021 / Published online: 21 June 2021

(C) The Author(s), under exclusive licence to Springer Science+Business Media, LLC, part of Springer Nature 2021

\begin{abstract}
Executive term limits are evidently under stress in many jurisdictions. One mode in which they are evaded is through the formal revision or abrogation of a constitution. Such a process accelerates a pernicious cycle in which constitutional non-compliance begets constitutional instability, which in turn begets subsequent non-compliance. Such a non-compliance cycle is a core problem in law, and one that deserves more careful examination in various domains. This essay unearths original historical evidence of term-limit provisions and executive tenure in an effort to illuminate and evaluate the phenomenon. A background concern is that of international (and domestic) approaches to term-limit evasion. One intellectual response is that of militant democracy. The logic of that approach would imply the entrenchment and protection of term limits, which would presumably disrupt the cycle of non-compliance.
\end{abstract}

Keywords Democracy $\cdot$ Militant democracy $\cdot$ Term limits $\cdot$ Rule of law · Presidentialism $\cdot$ Constitutionalism

\section{Introduction}

What is more emblematic of institutional weakness than term-limited Presidents who help themselves to an extra term? The very act seems to defy the goal of a society ruled by law as against one by particular individuals-a goal that reaches back at least as far as Aristotle (Politics [c. 350 BC] 1988, p. 1282b). The act also seems to emasculate the legislature, whether the body blesses or condemns the act.

\footnotetext{
Submitted to Constitutional Political Economy. I appreciate earlier comments from Leiv Marsteintredet, Markus Böckenförde, Dan Brinks, Steve Levitsky, Victoria Murillo, Gabriel Negretto, Fran Hagopian, Charlotte Heyl, Mariana Llanos, Jeff Staton, Emilia Powell, Monika Nalepa, and three anonymous reviewers. As always, thanks to Tom Ginsburg and James Melton, partners in many aspects of the data collection and the ideas herein.
}

Zachary Elkins

zelkins@austin.utexas.edu

1 Department of Government, University of Texas at Austin, Austin, United States 
Historically, of course, such executive dominance (over the legislature and, therefore, over law) has been thought to be a particular challenge for Latin American democracy. The challenge continues today, seemingly unabated, at the same time that term limits continue to be erected in the region's constitutions. In this article, I dig more deeply into the efficacy of term limits since 1850 in Latin America. ${ }^{1}$ The question(s) are threefold. First, to what degree and how have term limits functioned as barriers to ambitious Presidents? Second, how can we conceptualize and theorize the "culture" that has developed around term-limit evasion, which seems to reproduce itself? Finally, can constitution makers design a kind of Presidentialism that disrupts this cycle. ${ }^{2}$

The empirical contribution centers on an analysis of a set of original historical data on written constitutions together with a dataset on the tenure of world leaders. The combination of these two sources of data helps to establish patterns in constitutional replacement and term-limit evasion in Latin America. One interpretation of these patterns is that the behavior of executives regarding term limits is tied almost inextricably, and in a mutually destructive cycle, to the survival of the constitutional bargain itself. In short, Presidents - in legalizing their evasion of term limits — often degrade the very same institutional structure that would stand against their evasion in the first place. And so on, cyclically. Indeed, I suggest that the case of term limits is an illuminating (if especially pernicious) one in which to understand a common problem in institutional design more generally, one I will call non-compliance cycles. These sorts of vicious cycles would seem to be at the heart of institutional weakness (Brinks et al. 2019).

What to do about this sub-optimal state of affairs? The first step is to understand the philosophical tensions in the case for term limits. Like many restrictions, those on the number of terms of office can be both defended and excoriated on democratic grounds. So, while the idea of rotating leaders seems utterly sensible and democratic, creative lawyers and obliging courts have argued that such laws are antithetical to democracy. Indeed, one of the noticeable trends in international jurisprudence has been a shift in high-court opinion towards the view that term limits violate political rights. Arguably, the dissenting view deserves some intellectual reinforcement against these prevailing winds. In this spirit, I unearth the idea of militant democracy - a founding principle of anti-fascist constitutionalism. My sense is that the case for hardening term limits fits with aggressive elements such as party bans and other mechanisms of militant democracy that prize the preservation of democracy over liberalism. I suggest that those who are seeking to re-balance the debate over term limits could profit from this conceptual frame.

\footnotetext{
1 In at least one analysis (Fig. 1), I include countries in all of the Americas south of the United States. Otherwise, the analysis is restricted to those that evolved from Spanish or Portuguese rule, plus Haiti.

${ }^{2}$ I bracket the idea of assembly-confidence executives, whose flexible departure date presents a solution to fixed-term Presidents, and limits on such. True, some prime ministers are subject to term limits, but they represent an uncommon species.
} 


\section{Term limits as Parchment Barrier in Latin America}

Admittedly, one reason that term-limit evasion is so animating and pressing, is that it has infected the world over. But in Latin America, the land of Presidentialism, citizens have been battling this disease longer than anyone. The historical evidence in the region is rich and deep enough to keep Political Scientists and Historians busy for another six generations. And previous generations of Latin Americanists have been here before. One early benchmark is Russell Fitzgibbon's (1940) mid-century work on continuismo, the wonderful Latin American euphemism for Presidents who refuse to step down. Fitzgibbon was a student of constitutions and democracy, and one with a penchant for data. Still, he was not in a position to document fully the region's historical struggle with term limits. So we continue. And of course, that we take up an institutional challenge noted 70 years ago leads one to wonder whether Presidentialism can be inoculated against such a problem at all, or whether the problem is culturally endemic. The question, like all institutional questions, is whether stateways can change folkways, to paraphrase Sumner ([1906] 2011). I believe they can, and part of what we are about is the continual search for a vaccine against widespread norms of term-limit noncompliance.

\subsection{Term limits are quintessentially constitutional}

But testing and contact tracing is the first step in any of this vaccine work. ${ }^{3}$ So I begin by establishing some historical facts about term limits and their record and relevance in Latin America. I draw from original data on written constitutions from the Comparative Constitutions Project (Elkins and Ginsburg [2007] 2021). As a rule, an exclusive reliance on such documents is folly, as higher law can be misleading or incomplete, as any number of scholars will be (too) quick to point out. But in the case of term limits, neither interpretation nor incompleteness is a concern. On the first charge, it is difficult to imagine misinterpretations of Presidential term length or number, and on the second, such restrictions are nearly always inscribed in written constitutions. Exceptions to the latter exist; one is pre-WWII United States, as I describe below. ${ }^{4}$

\subsection{Latin America: the natural habitat of term limits}

As part of my larger study of the constitutional genre (again, Elkins and Ginsburg [2007] 2021), I have now read 245 of the 271 Constitutions that have been written

\footnotetext{
3 Pardon the analogy, which is a function of writing during a pandemic.

4 Marsteintredet and Uggla (2019) have produced an excellent data set on term limit and term length in Latin America, which is not based exclusively on written constitutions. A comparison of discrepancies between their dataset and that of the Comparative Constitutions Project reveals very few substantive differences.
} 


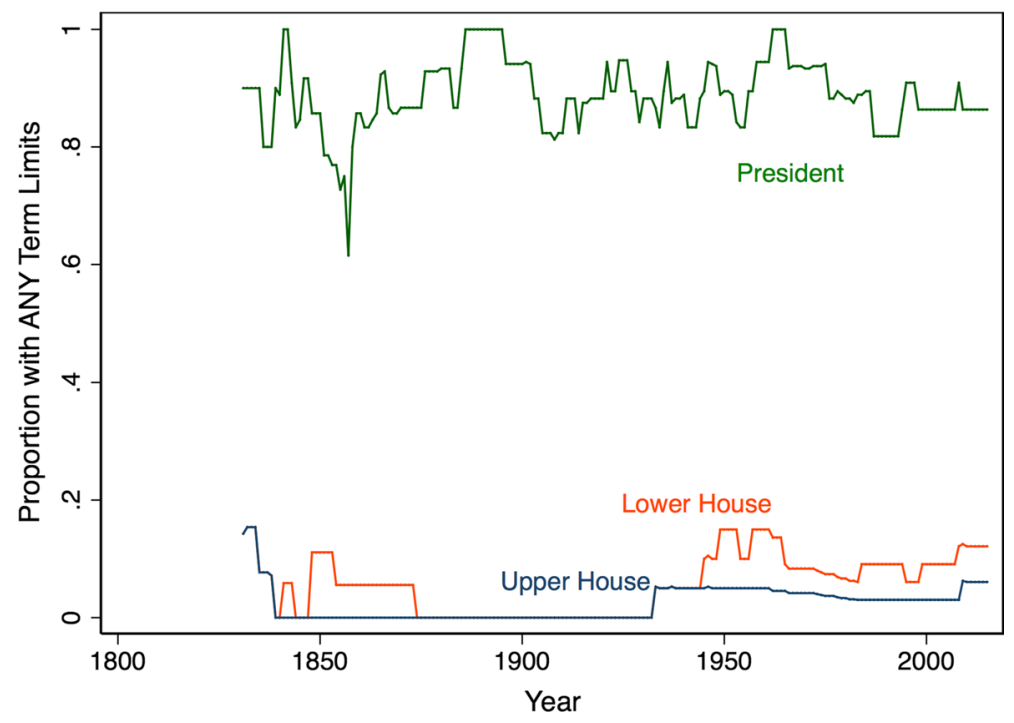

Fig. 1 Term Limits over Time, for Presidents and Legislative Houses in Latin America. N.B. Term limits include any of the four categories of term limits identified in Fig. 2

in Latin America between 1801 (Haiti) and 2015 (Dominican Republic); I have also read 573 of the 610 formal amendments to these Constitutions. ${ }^{5}$

The texts reveal that there is nothing new about term limits in the region; such limits are as old as the first constitutions. ${ }^{6}$ Not only that, but they are also nearly universal, and always have been. Figure 1 shows some of this consensualism. At three time points, every single Latin American constitution provided for executive term limits, and rarely has their prevalence dipped below 85 percent. Importantly, the Latin American experience pre-dates the formal institution of limits in the United States, a relevant reference point for drafters in the region. For more than a century, a two-term limit seemed to be the informal norm in the United States until the Franklin Delano Roosevelt presidency, an extended four-term administration that triggered the formal adoption of the two-term limit. By contrast, Latin American constitutions formalized some limit almost from the start.

What Fig. 1 also shows is that, with respect to the legislature, the provision is highly asymmetric. Legislatures - whether the lower or upper house-by and large have not operated with term limits. This gap persists despite presumably good theoretical reasons for legislative limits. So, we might consider the vertical

\footnotetext{
5 There may be more than this universe of 271 Constitutions and their 610 amendments, but if there are, they have not come to light in the 15 years that our project has operated. Subtraction of these quantities reminds us that 26 Constitutional texts have been lost to history, or at least to our discovery process.

6 Those interested in origin stories should note that our data suggests that the first occurrence of an executive term limit was in the short-lived French constitution of 1795, which forbade successive terms but allowed non-successive ones. Three years later, the Swiss constitution adopted the same provision as did the constitution of Gran Colombia in 1822.
} 


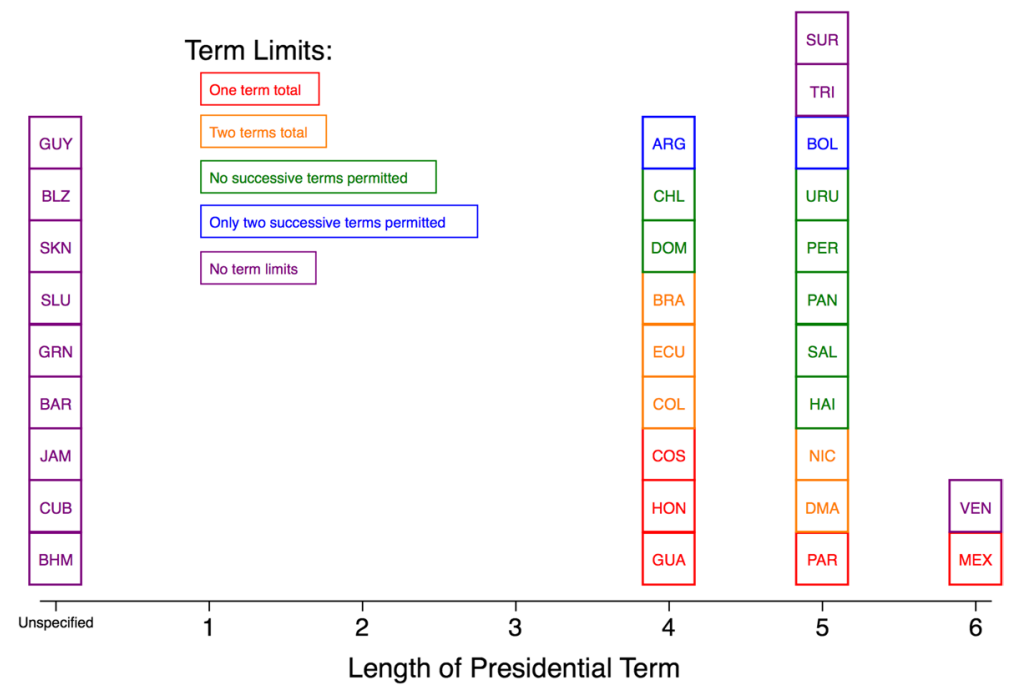

Fig. 2 Term lengths and limits in the Americas (c. 2019)

white space in Fig. 1 that appears between 10 and 90 on the y-axis as more evidence that the challenge of constraining ambition has been seen as a problem particular to executives, not legislatures. Of course, scholars of Latin America have long taken executive (over-)ambition as one of the persistent challenges of democracy in the region. But that constitutions in Latin America-many of which were written at the behest of executives themselves-would almost universally provide for limits year after year is noteworthy and, perhaps, puzzling.

Term limits come in several varieties-for example, one or two (or more) terms, the allowance of non-successive terms, etc. And of course, it is important to think not only of limits, but also of term lengths. At the extremes, term limits can be meaningless if terms are themselves lengthy. Think, for example, of the various countries that experimented with a term of eight years in the 19th century (e.g., Bolivia, Ecuador, Mexico, and Colombia) and then later, perhaps more memorably, in Pinochet's Constitution of 1980. Figure 2 shows the distribution of both of these variables among those constitutions currently in force in the Americas. Interestingly, we see some variation in the number and kind of limits among those countries with fixed terms (note that Fig. 2 includes some of the Parliamentary regimes of the Caribbean, to remind us of the existence of at least some variance in the region). In Fig. 2, one notes that the modal term length is now five years, which would seem to be a decided shift from the fouryear term that had become the staple of presidential regimes in the Americas. Figure 3 documents this shift more formally in half-century snapshots. By mid20th century, Latin American Constitutions had shifted to either five- or six-year terms. As it happens, this upward shift in length is coincident with an informal easing of executive tenure restraints-informal, that is, in ways that I describe 


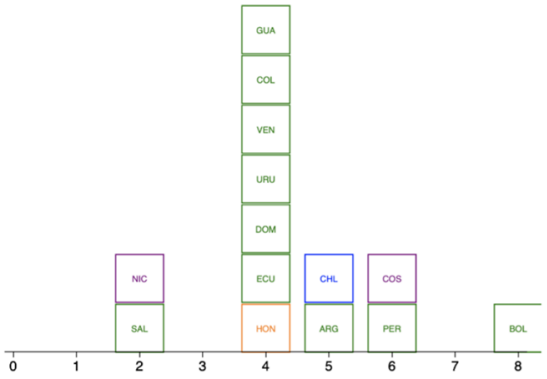

(a) 1850

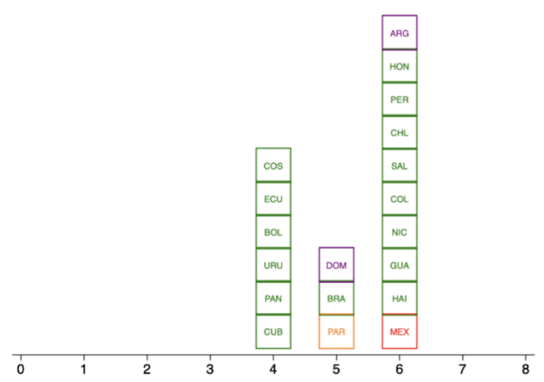

(c) 1950

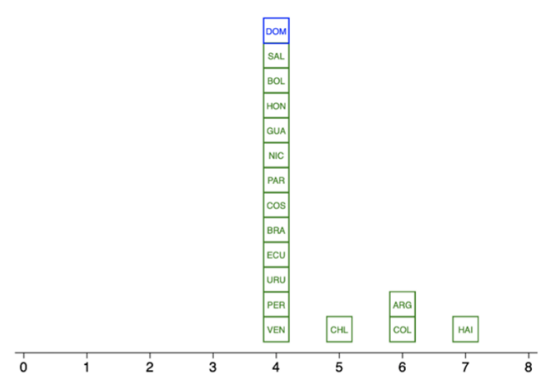

(b) 1900

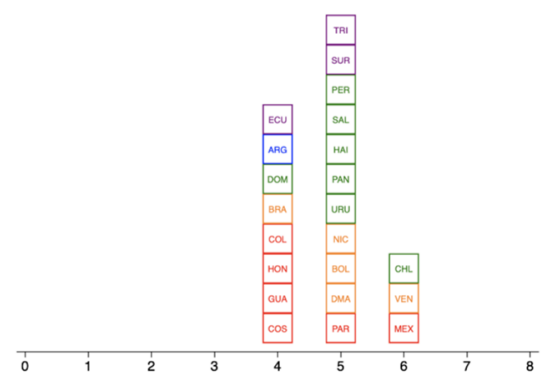

(d) 2000

Fig. 3 Term lengths and limits since 1850 in Latin America. N.B. Same legend as Fig. 2

shortly. It is also worth digressing to identify this shift as further evidence in the drift from the U.S. Constitutional model.

\subsection{Term-limit evasion}

Non-compliance with constitutional edicts is almost a default assumption in some intellectual quarters, where the documents are shelved as fiction. Madison, for one, worried about parchment barriers in the same way that we think about our New Year's resolutions. Constitutions are, after all, hopeful documents that embody all sorts of aspirational elements. And we should always remember that constitutions include ideas that sounded good at the time and to some (not all) citizens and their representatives. Regardless, evidence has come trickling in that constitutions can be remarkably binding on some matters at least. Chilton and Versteeg (2020), for example, find that collective rights such as the freedom of religion, which are championed by groups such as organized religion and labor, exhibit high degrees of compliance. Also, Amick, Chapman, and Elkins (2020) show in the context of balanced budget provisions that simply-interpreted and face-legitimate rules make for the kind of rule most likely to generate compliance. In this vein, one may think that commitments to fixed Presidential terms would be clear and legitimate enough that oppositional forces would be able to 
coordinate resistance to a transgressing executive. But executive ambition, especially coupled with mass appeal, can be a powerful thing. The liberator Simón Bolívar himself famously angled for a continuation of power, a powerful precedent. Indeed, Bolívar established what would come to be a time-honored tradition of insisting on term limits as a core tenet, only to take the exact opposite position once in power. Once in office in Bolivia, he argued for a life term:

The President of the Republic, in our Constitution, becomes the sun which, fixed in its orbit, imparts life to the universe. This supreme authority must be perpetual. (Quoted in Carey 2003,121)

It seems that even the most scrupulous would-be Cincinnatus can entertain visions of an extra term. It's hard to imagine a more determined position against continuismo than that of Cuba's Gerardo Machado, who served almost two terms as President from 1925 to 1933 . His campaign in 1924 was distinguished largely by his emphatic pledge to serve one term. His campaign manifesto stated, "A liberal president cannot be re-elected-this is now a noble tradition, the most noble of this party" (Fitzgibbon 1940). Well into his first term, his position seemed to have only hardened. In July 1927, he assured his colleagues:

A man whose lips had never been defiled by a lie, would lower his dignity, and dishonor himself, if after a political labor of twenty-five years during which he opposed the principle of re-election with the word and the sword in two revolutions, he should now accept the principle for himself. (quoted in Fitzgibbon (1940))

What a difference a year makes. The 1928 election saw him elected to a second term of office, this time for six rather than four years, following semi-legal revisions to the constitution specifying single six-year terms, a la the Mexican constitution of $1917 .^{7}$ Alas, his 1927 words may have been prophetic and served as something of a comeuppance; he was ousted prematurely in 1933 (when a second four-year term would have ended) largely by an opposition incensed by his continuismo. Bolívar and Machado are not alone in their apparent hypocrisy, or at least cognitive dissonance. Carey (2003) adds Peron to the list of those who opposed continuismo vehemently when out of power only to embrace the idea once in office, which may well be a long list (see the discussion in Llanos (2019)).

Because of the seemingly irresistable lure of an extended term, term limitseven when constitutionalized - have something of an optimistic, perhaps unrealistic, quality about them. The historical landscape-especially in Latin Americawould seem to be littered with abandoned constitutions that stood in the way of executive ambition.

A typical case is the short, unhappy life of Brazil's 1934 Constitution. Modeled after the Weimar constitution, the 1934 document extended political rights to

\footnotetext{
7 "Semi-legal" since the hand-picked constituent assembly seems to have acted outside of its instructions from the legislature (see the telling memo from U.S. Secretary of State Cordell Hull to the newly installed U.S. Ambassador, May 1, 1933 (Foreign Relations of the United States 1952)).
} 
most Brazilians, established a strong judiciary, and strengthened the legislature. President Getulio Vargas chafed under the charter's restrictions, including one that would have prevented his reelection in 1938. Not to be so curtailed, Vargas declared the constitution null and void in 1937 and replaced it with a new document, one that gave his administration considerably more room (and time!) to operate. More recently, Alberto Fujimori in Peru and Hugo Chavez in Venezuela, unable to utilize the normal amendment process because of legislative opposition, oversaw the replacement of their countries' constitutions in 1993 and 1999, respectively. The new documents extended the presidential term.

So, a constitution's demise can come at the hands of self-serving executives. But we also know of constitutions that survive such executive ambition, either by formal amendment, creative judicial interpretation or, perhaps more rarely, by the enforcement of their limits. In the last thirty years, for example, a number of Latin American presidents (notably those in Brazil, Argentina, and Colombia) were able to put through constitutional amendments that lifted limits on their terms and facilitated their re-election. In these cases, the executive managed to retrofit the constitution to his otherwise extra-constitutional transgression. Even though the constitutional document was mostly preserved during these episodes, one can still think of these as evasions of term limits, since they are transgressions of the limits of the original constitutional contract under which the leader took office.

Finally, consider the case of Mexico, a paradigmatic case of no transgression at all, whether extra- or intra-legal. Since its adoption in 1917, the current Mexican constitution has maintained a strong one-term limit for the President, a limit that has not been successfully broached.

Some of the theory that I advanced in a book with Ginsburg and Melton (Elkins et al. 2009) accounts for these cases of replacement, adaptation, and no-transgression. Part of that theory rests on the legitimacy that is conferred on long-standing documents. So, in Venezuela, a country with 24 constitutions since independence, constitutions may lack legitimacy as entrenched documents. When amendment proved difficult in 1998, President Chavez "merely" replaced the quasi-legitimate document to extend his term. By contrast, the Mexican 1917 constitution survives, un-transgressed, in large part because of the enormous legitimacy embodied by that document. The 1917 constitution was widely admired and widely copied, even in the years immediately following its promulgation, but certainly after Lazaro Cardenas had fulfilled many of its aspirational pledges in the 1930's. Its level of legitimacy contrasts sharply with that of the 1934 Brazilian document, which had very few come to its defense, especially after only three years in force. The cases of amended constitutions in the 1990's exhibit the characteristics that we would expect of an enforceable but adaptable constitution. Not only did these charters possess a fair amount of legitimacy, but they boasted a fairly flexible amendment rule. The 1988 Brazilian constitution, for example, requires two consecutive votes of $3 / 5$ approval by legislators for passage of an amendment-only slightly more stringent than the simple majority needed to pass legislation. Had the amendment procedures in these cases been more inflexible-for example, that of Bolivia's 1828 document 


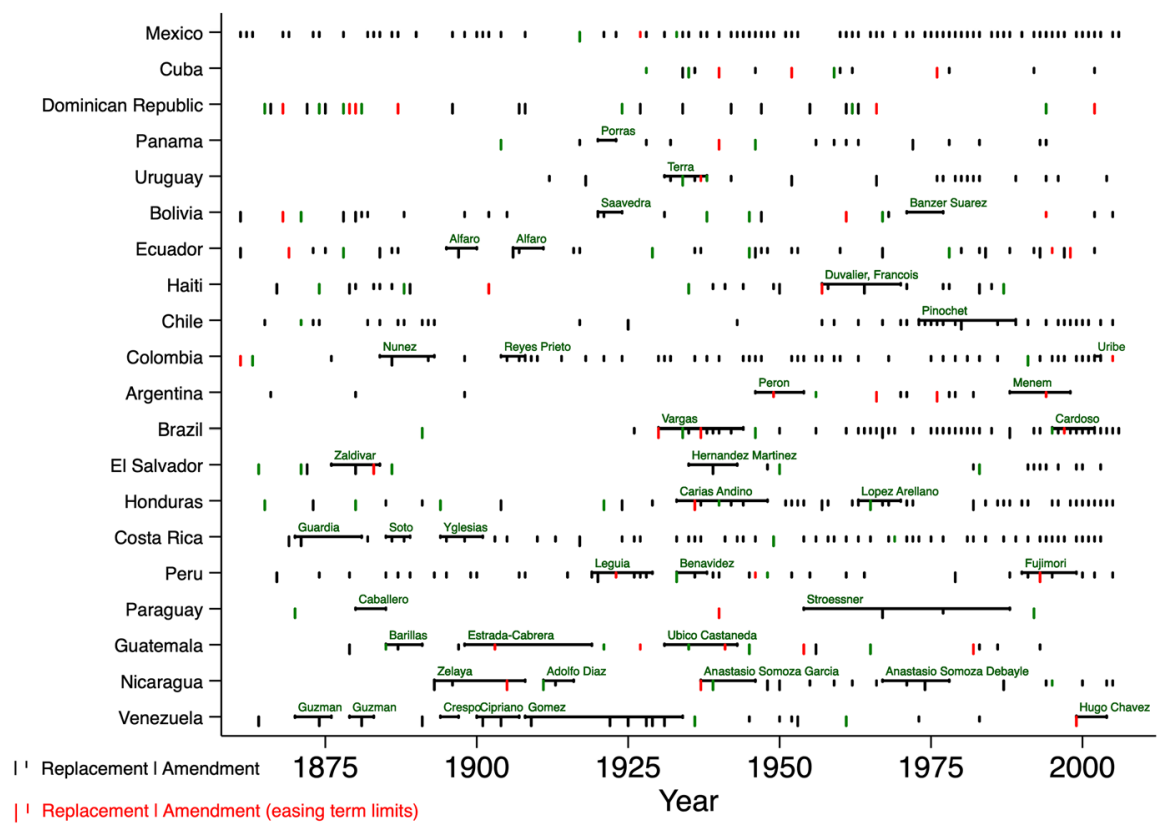

Fig. 4 Latin American leaders that have served longer than constitutionally allowed (according to the constitution in place at first term)

that forbade any amendment until 1838 — such adaptation to executive transgression would have been considerably more difficult.

\subsubsection{Patterns of evasion}

I will return to the compliance benefits of long-standing constitutions in the next section. But first, I turn more systematically to the evidence on term limits, executive evasions, and constitutional demise. I assess the prevalence of executive evasion by connecting our Comparative Constitutions Project data with data on leadership (heads of state) collected by authors of the Archigos project (Goemans et al. 2009). The union of these two datasets allows us to identify leaders who wound up in office longer than their constitution at their inauguration would have allowed. Figure 4 depicts chronological patterns of constitutional change (both generally and with respect to term limits) as well as executive evasion. ${ }^{8}$

First, a clarification of the figure's notation. The vertical hash marks that span the country series represent either constitutional replacements (the taller marks) or amendments (the shorter ones). The red versions of these marks identify those changes that amount to an easing in term limit provisions (e.g., from one to two

\footnotetext{
${ }^{8}$ Note that Marsteintredet (2019) describes a set of historical term-limit patterns based on an alternative set of constitutional measures.
} 
terms). The horizontal bars identify those leaders that have overstayed the time allotted them by the constitution as stipulated at the time of their inauguration. The length of the bar represents the total time in office.

Consider some observations about these patterns. First, note that nearly every country has some history of executive overstay since 1860. The three exceptions are Mexico, Cuba, and the Dominican Republic. I remarked upon Mexico's remarkable constitutional fealty above. In the case of Cuba, Fidel Castro's executive tenure is quite possibly record-breaking, but it is not rooted in any evasion of term limits so much as their periodic repudiation, as well as redefinition of executive roles. The aforementioned Machado was removed before he could overstay his original limit and Fulgencio Batista operated for six years in the 1950s mostly without the inconvenience of a formal term limit. Similarly, the Dominican Republic has, remarkably, not experienced overstay despite the fact that Rafael Trujillo spent 30 years in office from 1930-1960. None of the various constitutions that Trujillo commissioned during his tenure limited his term-most ignored the issue except for one that explicitly ruled out term limits. In some sense, continuismo is built into these two Caribbean cases.

It is also worth stressing the almost time-invariant incidence of this phenomenon. Lest we think of overstays as a pre-WWII problem, note that almost all of the countries with overstays (save Uruguay and Ecuador) have experienced overstay since 1970 - that is, in the recent memory of some half of the countries' citizens.

So, what is the connection between constitutional changes and overstay? Some distinct species emerge. ${ }^{9}$ Seven of the executive overstays were facilitated by the replacement of the country's constitution, a replacement that extended term limits and blessed the overstay. Six were made possible by an amendment that did so. So, in all, 13 of the 41 overstays were consecrated in higher law in some way. Call these, provisionally, constitutionally-assisted overstays.

But we observe another pattern that might be even more troubling for those concerned with weak institutions. 14 of the overstays are accompanied by new constitutions during the overstay-constitutions that do not alter executive term limits. It is too early to say what role these new constitutions played in the overstay, but some clues from other cases (e.g., Argentina) are instructive. It seems likely that Presidents used the occasion of the new constitution to sanction a reset of sorts. That is, Presidents could argue that their clock should start over with the inauguration of a new constitution. I'll call these "reset" overstays, which I hope is derisive enough to indicate some skepticism about their legitimacy. Baturo 2019 describes these as part of his avoidance category, and refers to Presidents as having "discarded" time and initiated a new "countdown." Both Baturo 2019 and Marsteintredet 2019 think of these as "grandfather" clauses.

The remaining third of overstays show no connection to written higher law. Call these extra-constitutional. Apart from constitutional adaptation, one wonders howif at all-leaders justified their overstay legally. Through an emergency declaration?

\footnotetext{
${ }^{9}$ I note here that Alexander Baturo (2019) has a useful typology of kinds of continuismo, which distinguishes between extensions, avoidance, and removals.
} 
An acquiescence of the judiciary or other legal organs? I do not attempt here a study of the jurisprudence of term-limit litigation, although I suspect that such a study would be a significant and rewarding contribution. Certainly, some recent controversies (e.g., Colombia and Honduras) have demonstrated that courts have something to say about the enforcement (or not) of term limits, and it would be useful to understand the competing perspectives in these jurists. These cases aside, it also seems quite likely that a fair number of term-limit evasions proceed without litigation. That is, Presidents simply ignore the rule without much justification.

\section{Term-limit evasion as non-compliance cycle}

The evidence suggests a strong culture of non-compliance with term limits in Latin American presidentialism. For those alarmed by term-limit evasion, the next step is to theorize more adequately the origins and maintenance of this culture. After all, the premise of law and institutions is that they should disrupt suboptimal cultural practices. Of course, one wonders whether institutions have such ability-surely many take Sumner's view that stateways cannot change folkways.

The point of departure for such theorizing is that term-limit behavior is mutually reinforcing; that is, one evasion invites another, a general effect that we can call a non-compliance cycle. ${ }^{10}$ I view this kind of behavioral reinforcement as effectively equivalent to culture, which I will think of as the normalization and predictability of certain attitudes and behavior. But the origins of this normalization matter, and we shall see that term-limit behavior is mutually reinforcing in somewhat more complicated ways than one might expect. Something different from, say, wellknown accounts of path-dependence and lock-in (Arthur 1989) or even Sikkink's (2011) justice cascades in which history also matters.

\subsection{Non-compliance as normed behavior}

Certainly the standard form of cultural reinforcement is operational in the term-limit case. That is, that leaders learn standards of behavior by observing other leaders, either historical figures from the same country or contemporaries from peer countries. We note (above) that any sort of precedent starts quite early, with Bolívar no less. And clearly, Fig. 4 suggests that there is an abundance of models from which to choose. No one would doubt, I suspect, that continuismo has been highly normed behavior in Latin America for some time. And scholars have noted that some of this behavior is wave-like - that is, clustered in time and space-which many take to be a symptom of interdependent decision making. Fitzgibbon (1940) for example, concluded that imitation across proximate jurisdictions likely produced a hotspot of continuismo in the early 1900s in Central America and the Caribbean, the "Latin American Mediterranean" as early 20th-century scholars quipped unflatteringly.

\footnotetext{
${ }^{10}$ I introduce a new term with some reluctance, since I share Sartori's aversion to concept proliferation; yet, I am not sure that a relevant one exists.
} 
This kind of non-compliance cycle, I would suggest, is quite common and perhaps to be expected. We understand, quite naturally, the idea of "safety in numbers" when it comes to legally deviant behavior. This effect is obvious with motorists who venture beyond the speed limit, but only if accompanied by other motorists. And people are more likely to litter when others have done so (Cialdini et al. 1990). In some places, there is an explicit recognition of this effect, which guides behavior. Some years ago, I found myself wandering the streets of Hamburg, Germany early on a Sunday morning. The streets were utterly deserted of cars, but yet pedestrians waited patiently at crosswalks for the signal to cross. "Why such compliance?" I asked my hosts later. "Just in case a child is watching," came the response. Note, of course, that we might expect Presidents to be especially important in modeling this behavior. This example-setting is one reason that public health officials were so disturbed that President Trump refused to don a protective mask during the Coronavirus pandemic of 2020. Compliance modeling and compliance norms probably explains a good bit of law-abidingness, especially in domains in which enforcement is low.

\subsection{Non-compliance as normed behavior across domains}

That Presidents are evading the law introduces a second-order effect to these kinds of non-compliance cycles. That is, it is not just that term-limit evasion sets standards and norms for future and contemporary leaders who might consider their own evasion. It is also that term-limit evasion invites non-compliance in other aspects of law. If the leader of the country is willing to play fast and loose with a core tenet of the constitution such as executive rotation, what does that say about the violability of other aspects of this so-called sacred text? Perhaps these other limits are just as discretionary, albeit with the right justification and legal adjustment. These spillover effects on other domains are not dissimilar to the "broken windows" logic that Wilson and Kelling (1982) describe, and that New York City Police commissioners put into practice in the 1990s. The implication of that argument is that small but visible instances of illegality can lead to illegality in other, more serious, matters. Thus non-compliance may spiral from one "kind" of violation to another.

\subsection{Non-compliance and the gutting of constitutions}

I suggest that these variants of compliance-unraveling are well understood (at least in some domains of behavior) and that such effects are fully operational in the case of term limits. But there is another reinforcing effect that is also in play and is perhaps more destructive as it is more subtle. Consider again that when Presidents engage in continuismo, they are more often than not revising higher law to justify their extension. On its face, this revision may seem unproblematic. It may well be that a legal justification is better than none at all. But a concomitant concern has to do with the collateral damage that comes with constitutional revision/demise. Executives that replace a constitution have done away with constitutional structures that stood in their way-constitutions that, possibly, had otherwise served the country adequately. What sort of costs come with this loss, this constitutional "destruction," 
if you will? My sense is that constitutional replacement, on balance, degrades constitutional compliance and reinforces non-compliance cycles.

\subsubsection{The important effects of constitutional maturation}

Much of this question turns on how one feels about constitutional aging. I have dealt with this question tangentially with my co-authors elsewhere (Elkins et al. 2009). Certainly, there are distinct benefits and costs to those constitutional systems that persist. So, for example, enduring constitutions provide some sense of stability and predictability at the expense, perhaps, of gaps in representation and institutional renovation. But a central hope for long-lasting constitutions is that they work more effectively as they age. I take the opportunity to think here about why that would be. In the Endurance of Constitutions my co-authors and I followed a line of thinking in which constitutions play an important role as coordination devices (Weingast 1997; Ordeshook 1992). Under this line, constitutional enforcement depends on citizens, who are, after all, the only ones left to challenge an overzealous executive. In order to solve the coordination problem of standing up to an executive and her armed forces, citizens need to understand when the executive has crossed the line. Agreement upon the location of that line requires that citizens know and appreciate their constitution - two things that increase with time. In this sense, cutting short the life of a constitution is potentially debilitating to the rule of law, whether the reason is merited or not.

These beneficial effects of maturation require more theorizing. Think for a moment how and when citizens learn anything about the constitution-anything that would be useful as operators in enforcement. Presumably, most learning (and allegiance) takes place during one's school years. This effect is twofold. On the one hand, it is likely that the only time that they will receive any information about the content of their country's constitution. Some educational systems, especially statefinanced ones, include a fair degree of civic instruction in their curriculum at the primary and secondary level, and in some countries such instruction might focus on the structure and guarantees of the national constitution. Citizens receive this crucial instruction at exactly the phase in their life-cycle in which it will have its maximal impact. We know from the rich literature on political socialization that political knowledge and attitudes form (and often crystallize) during their adolescent years. If individuals form their partisan and ideological identities then, it is no surprise that their "vision" of the constitution would be shaped at the same time.

For those raised and socialized (indoctrinated even) with a sense of what is constitutional, updates later in life may not stick. Our music collections are dominated by bands and genres that captivated us in our teens and 20's. Professors' bookshelves and syllabi are filled with titles that inspired them in graduate school. This imprinting early in the human or intellectual life cycle implies that the bite of constitutions might lag their introduction. That is, new constitutions (like any new technology) may simply not register immediately with those generations raised with other constitutions. One can think of this as constitutional culture change. Cultures change as generations turn over, which allows hardened and crystallized ideas of right 
and wrong to shift. This sort of shift is probably most obvious with identity rights, whether for women, racial minorities, or LGBTQ individuals.

Consider, then, the Tunisian Constitution of 2014. Citizens awoke on January 28, 2014 with a new set of rights, including the explicit mention of gender in the equality clause. ${ }^{11}$ Gender was a major issue in constitutional drafting and had led to street protests when the dominant Ennahada party floated a draft that referred to women's traditional roles in the family. But after the adoption of the new gender equality provision, those in elementary school would likely experience a constitutional education that would cement the vision of gender equality announced in the text. Some of those older than 21 may never think of the right to non-discrimination as part of the fabric of their polity or, if they do, it will not be until a critical mass of the younger generation brings them around.

Second, even if awareness of constitutional provisions were constant across generations, there may be increased respect for the document over time, perhaps even leading to something we might call veneration. Over time, the mere survival of a text could lead people to impute wisdom to its contents, which might mean that the cost of violating the provision increases.

Thirdly, there may be increased capacity among enforcers as the constitution ages. The judiciary, for example, is obviously a focal interpreter of constitutional rights. But in many situations, particularly in new democracies, the judiciary lacks the institutional capacity to serve as an influential interpreter. The public may not respect its decisions, or trust its judgment. The literature on judicial capacity suggests that, like most other institutions, courts develop over time (e.g., Ginsburg (2003)). The same is likely true of police, prosecutors, ombudsmen, health bureaucracies and teachers. When new enforcement institutions are created as part of a constitutional reform, they will need time to develop. As bureaucratic capacity grows over time, so too does the possibility of implementing constitutional promises.

Beyond an expansion in capacity, time may increase the shared understandings of rules among enforcers. Even if a constitution is adopted in a context of established institutions, they may need time to learn the new constitutional rules. Individual cases may arise that establish important precedents for what the constitution means. This information can spread to government institutions and the public, increasing the probability that the rules will be enforced.

For all of these reasons, it seems quite likely that constitutions get better with age. In some parallel work, Ginsburg, Melton, and I have begun to test these ideas. Our analysis suggests that, in fact, constitutions are more effective as they age (Elkins et al. 2016). These conclusions are based on analyses of the association between $d e$ jure constitutional guarantees of certain human rights with de facto enforcement of the same rights, conditional on when the rights were enacted.

\footnotetext{
11 Article 21 replaced article 6 of the prior constitution, adding the words in bold: "All citizens, male and female, have equal rights and duties, and are equal before the law without any discrimination."
} 
Table 1 Which leaders write new constitutions?

\begin{tabular}{lll}
\hline & Worldwide & Latin America \\
\hline Years in office & 1.11 & 1.15 \\
& {$[0.01]$} & {$[0.04]$} \\
Overstayer & 4.18 & 3.61 \\
& {$[1.15]$} & {$[1.44]$} \\
Constant & 0.12 & 0.10 \\
& {$[0.01]$} & {$[0.02]$} \\
Pseudo- $R^{2}$ & 0.13 & 0.12 \\
$N$ & 1,898 & 583 \\
\hline
\end{tabular}

Logistic regression

Units are the cumulative records of chief executives of independent states from 1875-2006

Dependent variable: executive presided over at least one constitution $(\mathrm{y}=1)$ or $\operatorname{not}(\mathrm{y}=0)$

Coefficients expressed as odds ratios; standard errors in parens

\subsection{The argument summarized}

If some of the dynamics of term limits and constitutional health sounds circular, they should. The implications of the way constitutions constrain executives and the way executives evade constitutions suggest a pernicious feedback loop of the worst kind. Let's summarize the logic of the argument.

First, we need to understand that ambitious executives are one, if not the, most frequent causes of death of a constitutional bargain. Admittedly, I have previously emphasized different risk factors associated with constitutional demise (Elkins et al. 2009). Namely, risk factors associated with the content of the constitution itself, factors my co-authors and I emphasized because of their malleability. Nevertheless, in all of that work, it has been abundantly clear that executives were the most frequent proximate cause of death, whatever the constitutional conditions. Second, an executive's assault on a constitution can be direct or indirect. It is direct in the sense that executives can simply replace an in-force constitution; indirect, in the sense that their actions of evasion or discretionary treatment of the law harm the legitimacy of the document. Third, we should understand that transgressions against a constitution (such as an evasion of term limits) are most likely to occur under conditions in which citizens are not especially attached to, or knowledgeable of, the constitution. Fourth, such conditions of attachment and knowledge are positively associated with the age of a constitution.

I hope that one can understand the vicious cycle in this logic well enough. One way to summarize the dynamic is thusly: society needs a well-established, highly legitimate constitution in order to guard against an executive's evasion of term limits, but it is exactly executive evasion that either directly or indirectly threatens the existence and/or legitimacy of a constitution. A classic Catch-22. Or, to return to Sumner. Stateways can conceivably change folkways, but it is more difficult if those same stateways are not just ignored but actively degraded by folkways. 


\subsection{Evidence of non-compliance cycles}

Cycles-exactly because they are recursive-are not simple causal processes to demonstrate. However, we are fortunate to have good historical data on both executive evasion and constitutional replacement, which provides significant empirical leverage. Recall that the theorized connection is not only that executive evasion is legalized and legitimated by constitutional replacement, but also that frequent constitutional replacement itself encourages executive overstay. The cyclical effect implies at least two empirical tests.

\subsubsection{Evasion and constitutional replacement}

The first question is whether instances of term-limit evasion are coincident with instances of constitutional replacement. Such an association would be consistent with an argument that constitutional replacements are deployed-either before or after-in the servicing of evasion.

One approach to the analysis is to investigate those chief executives that preside over the replacement of a constitution. We will assume that executives in power at the time of a constitution's drafting are at least highly supportive-if not the (ghosted) author-of the constitution written in their tenure. Given that constitutions are sometimes vanity projects by hubristic leaders, this attribution makes a bit of sense, as much as it feels excessively lionizing. The question is whether leaders who overstay during their tenure are more likely to author (or commission) a constitution than are those who exit punctually, controlling for total time in office? Table 1 shows the results of a logistic regression of an executive's authoring (or not) on (1) whether or not their record includes an overstay, and (2) time in office. The model is run on two samples: (1) 1,898 leaders, worldwide, from 1875 to 2006, and (2) 583 leaders from Latin America in the same time frame.

The results suggest that overstay and constitutional replacement are highly coincidental. Leaders that overstay are roughly four times as likely (odds ratios of 4.18 and 3.61, depending upon sample) to author a new constitution than are those who do not overstay. I emphasize that this regression controls for time in office, which should correlate with both overstay and authorship. With each year in office a leader is 1.11 times as likely to replace a constitution. Note that the constant in the model represents the baseline odds of replacing a constitution —odds that are quite low $(0.12$, in the worldwide sample, which suggests that roughly one in ten leaders will write a constitution in their tenure).

Of course, there are many reasons for constitutional replacement, and we can estimate the overstay effect in a multivariate model as well. Elkins et al. (2009) build a comprehensive series of models of constitutional survival in which they assess a wide variety of risk factors. In results not reported here, I include executive overstay in a replicated model with a full set of predictors drawn from both the country setting and the content of the constitution. The question is whether constitutions that co-occur with an overstay, in any part of their tenure, exhibit a shorter lifespan, ceteris paribus. As with the results above, overstay appears to be robustly associated with constitutional morbidity. 


\subsubsection{Constitutional fragility and overstay}

The second, and somewhat reciprocal, question is whether historical constitutional fragility predicts constitutional overstay. Are constitutional overstays more likely in settings that have experienced frequent turnover than they are in those that have been comparatively stable? Consider a simple bivariate test of such. We will predict the probability of overstay with a measure of historical constitutional stability, calculated as the number of constitutional replacements in a country's history prior to that year, divided by the years since the country's birth (call this a yearly risk of replacement). So, the United States had risk score of 0.004 in 2002, whereas Haiti's score was 0.11 in the same year. It is an imperfect measure, but should provide some sense of whether overstay is related to constitutional stability. We can assess the relationship with a logistic regression of overstay on historical fragility. The unit of analysis here is the leader, who are given an overstay score of 1 if they ever overstayed in their career, and 0 otherwise. The yearly risk of replacement is averaged over the course of the leader's tenure.

The results suggest a modest, but positive relationship between the two variables. The odds ratio on the risk variable is 10.14 , which suggests that full move on the theoretical range of the variable increases the risk of overstay by ten. A more realistic shift, say from the U.S. score to that of Haiti would increase the risk of overstay by a factor of 1.5. Again, it is a modest effect, but a noticeable one.

In summary, the historical data is consistent with the negative feedback story. Overstay appears to be both a product and a source of constitutional instability.

\section{Militant democracy and pre-emptive approaches to term-limit evasion}

How should, or can, one exit from such a negative cycle? One option, it would seem, would be to preserve the constitution by eliminating term limits altogether. Some might see that as the more realistic and less delusional approach. Why make futile commitments to a rotation in office, which are evidently discretionary and that throw into peril the constitutional bargain? Yet the fact that almost all Latin American constitutions have retained an executive term limit suggests the value of rotation and, perhaps, the determination to achieve it.

Another option is the opposite one: that is, to pre-empt any attempt at executive overstay. But what would that look like, and how could one justify it intellectually? One point of departure is the concept of militant democracy, which Loewenstein (1937a and 1937b) introduced as an answer to 20th-century Fascism (see also, Muller (2012)). A militant approach (known also in its German as streitbare, or wehrhafte Demokratie ${ }^{12}$ ) recognizes that democracy has the inconvenient predisposition to accommodate its antagonists and seed its own destruction. The answer,

\footnotetext{
12 An anonymous reviewer notes that some scholars prefer to reserve streitbare and wehrhafte for the German context, and argue that the meaning is stretched when applied outside of a post-fascist context.
} 
according to Loewenstein (1937a), is to deprive would-be authoritarians of the means (i.e., rights) of organizing their anti-democratic program.

A pre-emptive, militant approach is possible in the context of term limits. The prototypical manifestation is to enshrine the term limit as an eternal (unamendable) part of the constitution. This idea has taken hold in twenty or so Latin American and African constitutions, particularly over the last twenty years. In a sequel to this article, I describe the practice, history, and efficacy of this legal device in more detail, as well as its philosophical connection to militant democracy (Elkins, forthcoming). Suffice it to say here that the device is no silver bullet, but that it does deter evasion. More importantly, the device reminds us that democracy's architects are not necessarily imprisoned in a cultural trap of executive hubris.

\section{Conclusion}

Observers of Latin American politics likely have an impression of Presidents' treating term limits as, at best, discretionary law. The analysis here of term limits in Latin American Constitutions suggests that the scope of the problem is potentially unbounded. Nearly every country has imposed term limits, of some sort, on each of its Presidents since the very first constitutions. And ever since Presidents have been term-limited, some have managed to evade these limits.

It appears that a strong culture has emerged in Latin America of accommodating executive evasion through a variety of mechanisms. Such evasions may be concerning for any number of reasons. On the one hand, evasions represent a direct violation of the rule of law and the epitome perhaps of rule by an individual as against that of law. Another concern is the unsettling and unseemly notion of an executive altering higher law - presumably a fundamental commitment across generations-in order to fulfill a highly particular and personal objective. These would seem to be acts of utter hubris, the exact opposite of the examples of Cincinnatus, George Washington, and any other executives that presumably know when to make a graceful exit.

It is possible to take a tolerant view of term-limit evasion. One can imagine that some discretion and flexibility in even the brightest-line law is helpful-especially in the case of emergencies, if not in that of "exceptional" statesmen and women. However, various implications of term-limit evasion lead me to have limited tolerance for the practice. One of the more pernicious aspects of evasion is how the act is embedded in a troubling feedback loop of institutional weakness, which I term a non-compliance cycle. Indeed, understanding this dynamic is important for understanding institutional weakness more generally. It seems likely that the same dynamic is at the heart of institutional instability and non-compliance across other domains of law. I recall in this article a conceptual framework for the defense of term limits in the face of such non-compliance cycles. That framework-militant democracy - was built to prevent the return of a different kind of authoritarian, in a different time, with different methods. Still, the framework may be valuable to courts that have, until now, lacked the intellectual firepower to safeguard an important element of democracy. 


\section{References}

Amick, Joe, Chapman, Terrence, \& Elkins, Zachary. (2020). On constitutionalizing a balanced budget. The Journal of Politics, 82(3), 1078-1096.

Aristotle. (1988). The Politics. Stephen Everson (trans.), Cambridge: Cambridge University Press. First published c. $350 \mathrm{BC}$.

Arthur, W. Brian. (1989). Competing technologies, increasing returns, and lock-in by historical events. The Economic Journal, 99(394), 116-131.

Baturo, Alexander. (2019). Continuismo in comparison: Avoidance, extension, and removal of presidential term limits. In Alexander Baturo \& Robert Elgie (Eds.), The Politics of Presidential Term Limits. Oxford: Oxford University Press.

Brinks, D. M., Levitsky, S., \& Murillo, M. V. (2019). Understanding institutional weakness: power and design in Latin American institutions. New York: Cambridge University Press.

Carey, John M. (2003). The reelection debate in Latin America. Latin American Politics and Society, 45(1), 119-133.

Chilton, Adam, \& Versteeg, Mila. (2020). How constitutional rights matter. Oxford: Oxford University Press.

Cialdini, Robert B., Reno, Raymond R., \& Kallgren, Carl A. (1990). A focus theory of normative conduct: Recycling the concept of norms to reduce littering in public places. Journal of Personality and Social Psychology, 58(6), 1015.

Elkins, Zachary. (Forthcoming). Militant Democracy and the Pre-emptive Constitution. Democratization.

Elkins, Zachary and Tom Ginsburg. ([2007] 2021). Characteristics of National Constitutions, Version 3.0. Comparative Constitutions Project. Last modified: June 17, 2021. Available at comparativ econstitutionsproject.org.

Elkins, Zachary, Ginsburg, Tom, \& Melton, James. (2009). The Endurance of National Constitutions. Cambridge: Cambridge University Press.

Elkins, Z., Ginsburg, T., \& Melton, J. (2016). Time and constitutional efficacy. In T. Ginsburg \& A. Huq (Eds.), Assessing constitutional performance (pp. 233-267). Cambridge: Cambridge University Press.

Fitzgibbon, Russell H. (1940). 'Continuismo' in Central America and the Caribbean. Inter-American Quarterly, 2, 56-74.

Foreign Relations of the United States, Diplomatic Papers of 1933, The American Republics, Volume V. (1952). Eds. Victor J. Farrar and Henry P. Beers. Washington: United States Government Printing Office.

Ginsburg, Tom. (2003). Judicial review in new democracies: Constitutional courts in Asian cases. New York: Cambridge University Press.

Goemans, Henk E., Gleditsch, Kristian Skrede, \& Chiozza, Giacomo. (2009). Introducing Archigos: A dataset of political leaders. Journal of Peace Research, 46(2), 269-283.

Llanos, Mariana. (2019). The politics of presidential term limits in Argentina. In Alexander Baturo \& Robert Elgie (Eds.), The politics of presidential term limits. Oxford: Oxford University Press.

Loewenstein, Karl. (1937). Militant democracy and fundamental rights, I. American Political Science Review, 31(3), 417-432.

Loewenstein, Karl. (1937). Militant democracy and fundamental rights, II. American Political Science Review, 31(4), 638-658.

Marsteintredet, L. (2019). Presidential term limits in Latin America: c. 1820-1895. In A. Baturo \& R. Elgie (Eds.), The politics of presidential term limits (p. 103). Oxford: Oxford University Press.

Marsteintredet, L., \& Uggla, F. (2019). Allies and traitors: Vice-presidents in Latin America. Journal of Latin American Studies, 51(3), 665-688.

Müller, Jan-Werner. (2012). Militant democracy. In The Oxford Handbook of Comparative Constitutional Law. Eds. Michel Rosenfeld and András Sajó. Oxford: Oxford University Press.

Ordeshook, Peter C. (1992). Constitutional Stability. Constitutional Political Economy, 3(2), 137-175.

Sikkink, K. (2011). The justice cascade: how human rights prosecutions are changing world politics. New York: WW Norton \& Company.

Sumner, W. G. (2011). Folkways-a study of the sociological importance of usages, manners, customs, mores and morals. Redditch: Read Books Ltd.

Weingast, Barry R. (1997). The political foundations of democracy and the rule of law. American Political Science Review, 91(2), 245-263. 
Wilson, James Q., \& Kelling, George L. (1982). Broken windows. Atlantic Monthly, 249(3), 29-38.

Publisher's Note Springer Nature remains neutral with regard to jurisdictional claims in published maps and institutional affiliations. 